Full length article

\title{
Looking for the perfect tweet. The use of data mining techniques to find influencers on twitter
}

\author{
Eva Lahuerta-Otero*, Rebeca Cordero-Gutiérrez \\ IME, University of Salamanca, Faculty of Business and Economics, Campus Unamuno, FES Building, 37007 Salamanca, Spain
}

\section{A R T I C L E I N F O}

\section{Article history:}

Received 26 April 2016

Received in revised form 4 July 2016

Accepted 22 July 2016

Available online 31 July 2016

\section{Keywords:}

Social influence

Influencers

e-WOM

Tweet elements

Twitter

\begin{abstract}
A B S T R A C T
The purpose of this study is to investigate influencers on Twitter to discover the characteristics of their tweets through PIAR, a unique data mining research tool developed by the University of Salamanca that combines graph theory and social influence theory. An analysis of 3853 users posting about two automotive Japanese car firms, Toyota and Nissan, reveals the characteristics influencers have on this social network. The findings suggest that influencers use more hashtags and mentions on average when they tweet, and their word count is fewer than those with less power on this virtual community. Surprisingly, they tend to include less embedded links on their posts. Additionally, influencers have on average a large number of people they follow and they clearly express their opinions and feelings (either positive or negative) when tweeting. The results broaden the understanding of how influencers write and behave on social networks when they communicate with their users' community. Further, it provides insights for practitioners and marketers on how to discover influencers talking about their brands by observing tweets' content.
\end{abstract}

(c) 2016 Elsevier Ltd. All rights reserved.

\section{Introduction}

In recent years, social media have transformed the worldwide web into a participatory community where both users and companies co-create, share and modify content. The importance and the attention that social media has gained is widely studied among the scientific community as their growth seems unstoppable. According to Social Media Today (2015) nearly half of the global population (3175 billion people) are Internet active users. Social media have become increasingly fashionable with 2206 billion active users, $87.2 \%$ out of which access through mobile platforms. This means 12 new active mobile social users join these platforms every second, meaning one million per day!.

All this incredible numbers have made brands realize the importance of social media to engage with customers in the digital world. Among all the different web 2.0 tools, microblogging sites have emerged as one of the most dynamic platforms for usergenerated content. Microblogs are a set of Internet tools where users publish short updates to friends and interested observers via text messaging, instant messaging (IM), e-mail or the web (Java,

\footnotetext{
* Corresponding author.

E-mail addresses: eva.lahuerta@usal.es (E. Lahuerta-Otero), rebecacg@usal.es (R. Cordero-Gutiérrez).
}

Song, Finin, \& Tseng, 2007). Twitter is the most worldwide used microblogging platform. Born in 2006, it has 320 million monthly active users (Twitter, 2015) $80 \%$ of which are mobile. According to the latest statistics (Internet Live Stats, 2015), 7077 tweet are sent every second, meaning $611,452,800$ tweets per day. Thus, is not surprising that microblogging platforms play a dominant role as a social medium that facilitates information sharing in many sectors such as news, travel or branding (Jansen, Zhang, Sobel, \& Chowdury, 2009; Parra-López, Bulchand-Gidumal, Gutiérrez-Tano, \& Díaz-Armas, 2011). Nevertheless, Twitter users also write on this social platform to complain about brands and share their frustrations (eMarketer, 2014). Consequently, by analyzing the information that users exchange, we can gain insights about their sentiments towards brands, companies, news or any other piece of relevant information. We refer to influencers as those individuals from a virtual community who are able to modify shopping behaviors of others (BusinessDictionary, 2015). Most brands try to involve influencers on their marketing campaigns, as professionals in the field believe they are effective to reach their commercial targets (Augure, 2015). Despite the efforts made by organizations and brands, the identification of influencers is still the main challenge for both companies and marketers (Augure, 2015; Pal \& Counts, 2011). On the same line, Ikeda, HattoriI, Ono, Asoh, and Higashino (2013) point out that research studying the community 
relationships through data mining techniques is still limited. Thus, the objective of this study is to analyze users' Twitter behavior and its impact on their social influence.

\section{Theory}

\subsection{Microblogging and virtual communities}

Many researchers and practitioners refer to virtual communities as self-sustaining social groups where members connect (Rheingold, 1993; Schuler, 1996). Virtual communities are more than just a way of sharing valuable information because their members can share all kinds of experiences and knowledge (news, software, links, images, music, videos, etc.) through this platform (Flavián \& Guinalíu, 2005).

There is an area of research in the literature addressing the uses of microblogging platforms as a means to do branding, viral marketing or electronic word-of-mouth (e-WOM) (e.g. Cha, Haddadi, Benevenuto, \& Gummadi, 2010; Hughes \& Palen, 2009; Jansen et al., 2009). It is also proved that Twitter is a valuable real-time tool to communicate emergencies to the public (Hughes \& Palen, 2009; Starbird, Palen, Hughes, \& Vieweg, 2010; Vieweg, Hughes, Starbird \& Palen, 2010). During mass emergencies, Twitter users send detailed information that help others to make better decisions such as warnings, road closures, evacuations, weather information

. (Corvey, Vieweg, Rood, \& Palmer, 2010). It is also true that microblogs and social network sites in general can constitute a powerful form of e-WOM (Erkan \& Evans, 2016; Jansen et al., 2009). From the examination of the past literature, we can observe how microblogs are suitable for information exchange in various, alternative settings for several reasons (Dharmavaram Srenivasan, Sian Lee, and Hoe-Lian Goh, 2012).

First, microblog users are not constrained to any rules or formats on what is an acceptable post, excluding the limitation of 140 characters on Twitter. Moreover, the posts they create become public, so the creation of this new content is immediately accessible and available to other members of the virtual community. Second, microblogs are a perfect platform to test the tone of the immediate interests, latest happenings and users' attitudes (Sankaranarayanan, Samet, Teitler, Lieberman, \& Sperling, 2009) as it is a reflection of their sentiments towards a fact that is currently happening. Finally, Twitter provides users with an automatic and instant feedback reaction from other members of the virtual community, which could be useful in terms of identifying the most influential members of the group (Goh \& Lee, 2011).

Nevertheless, in order to identify e-WOM processes, it is necessary to know which individuals have "the power to alter purchase decisions of others because of their authority, knowledge, position or relationship" (BusinessDictionary, 2015), known in the literature as influencers. As Verhoef, Beckers, and Van Doorn (2013) posit, social networks involve value co-creation because not all the ideas proposed by users would be equally interesting, and not all customers are equally influential. However, alternative groups of Twitter users pretend to gain social capital to leverage it to promote their tweets (Ghosh et al., 2012). They look for influence by means of interconnections with others so it is natural that they coincide as they follow and are followed at the same time. The theory of influentials states that only a few members of a society have the abilities to be extremely persuasive when passing along ideas to other users. Therefore, a marketing campaign that convince a small number of influencers can get extremely positive results with low budget (Messias, Schmidt, Oliveira, \& Benevenuto, 2013). Some authors consider that Twitter influence relates more with the diffusion and repercussion of tweets than with the number of followers a user has (Cha et al., 2010; Messias et al., 2013). This is the reason why we also need to consider the following metric (Using Twitter (2016) terminology, subscribing to a Twitter account) when evaluating users' social influence.

In order to follow conversations of a community, users need to follow other members so that their posts appear on their Twitter newsfeed. This differs from other social networks (Facebook for example, where you explicitly need that a user accepts a friend before the latter can see his/her publications) because a user can follow other user without requiring the permission of the latter. When they read a tweet from other user, they can show different forms of engagement. First, users can mark the tweet as favorite, meaning they like the content. Secondly, they can retweet the content as it is and pass along the message to their followers list, increasing its visibility and social impact. Lastly, users can use the information to write their own tweet by citing (by means of a mention) the original user post where they get the information. Because of the close ties created on Twitter, and since it is easy and costless, sometimes users follow others as a courtesy. Thus, the number of profiles following a user indicates popularity, but it is not necessarily related to his/her influence (Bigonha, Cardoso, Moro, Almeida, \& Gonçalves, 2010). Consequently, users that follow others indirectly increase their popularity, so more users can see tweets and some of them might eventually keep up with the tweets, as they are perceived as a source of credibility (Jin \& Phua, 2014). This means that social influence increases when a larger number of people have access to influencer's tweets. Consequently and to become an influencer, not only is it necessary to have a large list of followers to increase social capital (Jin \& Phua, 2014) but it is also important that the user itself follows many people to create strong and solid links in the virtual community (Okazaki, DíazMartín, Rozan-Suplet, and Menéndez-Benito, 2014). Therefore, we hypothesize:

H1. Users following a larger number of individuals on Twitter (following) will have greater social influence.

\subsection{Microblogging and word-of-mouth}

Literature refers to e-WOM as 'any positive or negative statement made by potential, actual, or former customers about a product or company, which is made available to a multitude of people and institutions via the Internet' (Henning-Thurau, Gwinner, Walsh, and Gremler, 2004 p. 39). Some studies claim that individuals also tend to trust opinions from people outside their immediate social network such as online reviews (Duana, Gub, \& Whinston, 2008). As a result, e-WOM can influence brand image, perceptions and purchase decisions (Reynolds, 2006; Urban, 2005), even though it is hard to stop or control an e-WOM campaign once started, as most of the time it is spontaneous and hard to influence.

Following the attention economy (Davenport \& Beck, 2002) and given the fact that brands compete for the online attention of potential customers, microblogging and its unique communication features need to be considered as an e-WOM form (Jansen et al., 2009).

As there is a strong competition in the social network sites field, firms need to identify those individuals whose influencers' networks are closely knit as they will be motivated to engage in viral dynamics which are seen as an opportunity of getting fun by sharing content (San José-Cabezudo and Camarero-Izquierdo, 2012).

Although e-WOM is less personal than face-to-face word of mouth, it can be more powerful because it is immediate, with global reach and accessible to others. This means information, reviews and e-WOM comments are available for customers before, 
during and after the different phases of the purchase decision process. Davis and Khazanchi (2008) study showed that e-WOM postings significantly explained changes in sales. On a recent metaanalysis of 1532 effect sizes across 96 studies covering 40 platforms and 26 product categories, Babić, Sotgiu, de Valck, and Bijmolt (2015) statistically demonstrates that on average, e-WOM positively correlates with sales, although its success depends on the platform, the product and the metric used. Park and Lee (2009) showed that negative e-WOM effects is greater than positive eWOM for experience goods than for search goods.

In terms of marketing as we have seen above, it is generally accepted that for e-WOM it is important to discover the characteristics influencers show when writing, so they can be easily identified. First, in terms of the number of words used, several authors have researched the average tweet characters that are more successful in terms of engagement in the virtual community. Benevenuto, Magno, Rodrigues, and Almeida (2010) included the number of words of each tweet in order to identify content attributes. Bennet (2014) found that an ideal twitter post is around 71-100 characters. Enge (2014) found that the longer the tweet, the better the chances of engagement (in the form of retweets and favorites). Lee (2015) also found that the ideal tweet length ranks from 120 to 140 characters (which is the maximum permitted by this microblogging tool). Therefore, and in line with previous research, we hypothesize:

H2a. Users writing longer tweets get more social influence.

Related to e-WOM communication in sentiment analysis, there has been limited research in the field of microblogging area (Jansen et al. 2009). Twitter content and sentiment analysis is not an easy field of study as tweets can contain a lot on information synthetized in only 140 characters. These messages can have positive, negative, sarcastic or ironic feelings simultaneously that content algorithms find it difficult to classify (Bifet \& Frank, 2010). Labelling tweets manually is arduous and expensive, if not impossible, as users can eliminate tweets after their publication and therefore numbers change.

Despite the difficulties, several efforts have been made by authors to understand better content and sentiment of tweets: Java et al. (2007) examined 1,348,543 tweets from 76,177 users to assess the style of use and Twitter users' intentions. Jansen et al. (2009) looked at Twitter accounts of brands to classify tweets over a negative to positive spectrum (no sentiment, wretched, bad, so-so, swell, great). Boyd, Golder, and Lotan (2010) focused on a list of retweeting reasons including relaying valuable content, endorsing a user or topic, favor conversation or personal reasons such as friendship. Naaman, Boase, and Lai (2010) designed a set of nine item tweets' categories including information sharing, opinions/complaints, statements, self-promotion, etc. Dann (2010) proposes an additional Twitter content classification into six broad categories that can be refined up to 23 subcategories including conversational, pass along, news, status, phatic or spam tweets. In the area of text mining, Hutchison and Kumara (2013) used a binary method to distinguish between a list of positive and negative tweets in order to build word clusters. Okazaki et al. (2014) conducted a classification analysis of tweets based on satisfaction, dissatisfaction, neutral or exclusion values by using automatic learning techniques combined into seven different algorithms.

Nevertheless, this research is unique in the sense that we propose a sentiment index ranking from -1 (most negative opinions) to +1 (most positive ones). This variable is extracted from every Tweet the user posts containing the keyword of the study. By means of this variable, we are able to determine the exact combination of positive and negative words of each users' tweet, so that we build a unique and accurate sentiment score of each of the Twitter users on the database. However, a user can be as equally influential by writing positive or negative comments about a specific topic so we consider this variable using its absolute value and we propose accordingly:

H2b. users showing sentiment (either positive or negative) on tweets will increase their social influence.

Finally, it is also important to mention that users generally engage in conversations on Twitter to talk about different topics. In order to determine trends, Twitter uses an algorithm that identifies topics that are popular now and they vary according to the users' followings and locations. Users call this list "trending topics". Twitter influence depends on the relative amount of content a follower receives. Since users are usually topic-sensitive, they will pay more attention to those tweets where the content is of him/her interest (Weng, Lim, Jiang \& He, 2010). Users generally have different expertise fields, so they tend to publish on subjects they manage. Therefore, in order to be useful and worthy, a tweet must include valuable content.

Lexical diversity is a ratio that calculates the number of unique words to total words. Therefore, it gives a quantitative indicator of the diversity of vocabulary of an individual when writing, but it also helpful to understand how broad or narrow the topic discussed in the community is. Russell (2013) affirms that individuals would prefer users with a more diverse vocabulary, as they will believe they understand the topic discussed better. We believe that users with a larger vocabulary would write topics that can be more interesting to their audience, meaning they manage a wider variety of subjects to engage users on a conversation. We hypothesize accordingly:

H2c. Users with high lexical diversity will get more social influence.

\subsection{Microblogging and content sharing}

To understand the motives of users to participate on a virtual community, research often refers to the uses and gratifications paradigm. This theory states that users will share content to fulfill a core set of motivations according to Dholakia, Bagozzi, and Pearo (2004). First, information value is a variable that makes participants to get and share relevant information. Users also get instrumental value when they use the information to complete a specific task such as making a purchase or solving a specific problem. Second, users get self-discovery value if they understand better their own personalities thanks to social interactions. Maintaining interpersonal connectivity is another added feature that encourages users to interact on virtual communities. Many users join the social platform as they feel lonely, insecure, helpless or they simply need to make friends. Social enhancement is therefore a value that participants obtain when they are accepted and welcomed in the community as well as their contributions. When users interact, besides connectivity and social enhancement they feel they belong to a group (group-referent) that dictates a series of established rules, norms and opinions. Lastly, social platforms always have an entertainment component, as their members can relax on an informal atmosphere by playing, chatting or interacting with others.

When members belong to a virtual community, they develop a social identity. This is an emotional state that fosters loyalty and group behaviors (e.g., Bergami \& Bagozzi, 2000; Meyer, Stanley, Herscovitch, \& Topolnytsky, 2002), that can enhance brand loyalty (Bhattacharya \& Sen, 2003). When we refer to virtual 
communities, we also need to mention group norms. These norms are a set of adopted principles that users voluntarily accept, as they are coherent with both the community goals and their individual motives (Postmes, Spears, \& Lea, 2000). When members of the community accept and follow them, their bonds to the group strengthen (Blanchard, 2008).

Social exchange theory is also fundamental when explaining the behavior of individuals in a group. Members of a virtual community usually exchange support in many ways. As any message is available for all group members, there is a perception that the whole group is supportive, even if only a few members actually create and distribute the message (Blanchard, 2008). This theory is based on the sense of reciprocity norm (Goulder, 1960) according to which individuals in virtual communities can help each other directly or indirectly if support and learning is provided to an entire group.

When users feel comfortable with the group, they often "share", by means of a retweet, content that other users could find interesting or relevant. By passing a tweet along, not only do users amplify the message, but they also validate it. Retweeting can be a form of social advocacy where members become supporters of a user or a brand (Malhotra, Malhotra, \& See, 2012).

The number of hashtags, retweets and mentions are classical ways of measuring Twitter engagement (Lee, 2015; Pal \& Counts, 2011). Cha et al. (2010), for example, built an influence score of users based on the number of followers, retweets and mentions of each Twitter account. By using hashtags (writing the \# symbol before a word), uses can easily identify trending topics and engage in the conversations they are interested in. Consequently, users include it when writing a tweet so that they can maximize the chances of diffusion. Hashtags organize topics according to tags that apply at a global level. Therefore, hashtags can increase the engagement rate (Enge, 2014). The same comment applies for mentions (writing the @ symbol before a Twitter username). As we have mentioned before, social networks create virtual communities with strong, close ties between members. It is natural for them to mention either the original source where they get the information from or some person who might be interested in the content. Mentioned users get a notification alert so they can know when someone is referring to them, so they can join the conversation, like or retweet the content or write a direct reply to the original user. Therefore, tweets containing mentions get higher engagement (Enge, 2014).

Regarding the use of embedded links on Twitter, recent literature offers contradictory results. On the one hand, Malhotra et al., 2012 study on 47 well-known companies on diverse business areas found that using embedded links would not help posts to be retweeted. Lee (2015) and Ross (2014) also found that using links does not contribute to increase Twitter interactions or engagement. In the same line, Enge (2014) found a minor impact of links on the chances of retweets and favorites. On the contrary, Boyd et al., 2010 analysis showed that the majority of analyzed retweets (52\%) contained a URL. In the same line, Bongwon, Lichan, Peter, and Chi (2010) Liu, Liu, and Li (2012) and Zarrella (2009) found empirical evidence that tweets containing links were more likely to be retweeted. Finally, Zhang, Peng, Zhang, Wang, and Zhu (2014) consider that the use of links contributes to information completeness since the strong restrictions of this social network in terms of characters (maximum 140 per tweet) is not sufficient compared to other social sites. Accordingly, we believe that the use of URL links could improve the completeness of influencers' information, mitigating the information volume deficiency in microblogging. Therefore, we propose the following hypotheses:

H3a. the use of hashtags on tweets increases social users' influence.
H3b. the use of mentions on tweets increases social users' influence.

H3c. the use of embedded links on tweets increases social users' influence.

In order to determine a user's influence on Twitter, there is a well-known tool known as Klout score. Klout uses Bing, Facebook, Foursquare, Google+, Instagram, LinkedIn, Twitter, YouTube, and Wikipedia data to create the score (Klout, 2016). Ranking from 0 to 100 , it represents a measure of the ability to generate actions on Twitter (comments, mentions, favorites, retweets ...). Although it is a well-known instrument, it depends on all social networks where the user has an active profile. Klout score is continuously changing accordingly, and it distinguishes between active users from influential users, whose actions and comments generate immediate actions from other members of the virtual community (Klout, 2016). Klout score is a combination of several attributes from several social networks where the user is active but there is no way to discriminate the individual influence that a user causes on a single platform using this indicator. This is the reason why only $3 \%$ of marketers consider Klout as a reliable source to measure social influence (Augure, 2014).

Nevertheless, brands engaging with influencers online believe that this relationship helps them with sales support and customer loyalty. Furthermore, links with influencers significantly improve visibility and brand value (Augure, 2015). This is the reason why the University of Salamanca, through the PIAR project, has developed a platform that is able to identify an alternative influence score, based on the contacts and followers of a Twitter user. Initially born for national security purposes, it has an enormous potential for academic and practitioners' use. By means of this platform, not only are we able to identify a users' influence network, but we are also capable of collecting important variables such as sentiment polarity, lexical diversity, average words (and characters) or the number of hashtags and embedded links used. Furthermore, we are able to unambiguously identify a Twitter user, together with its core social metrics.

Whereas most research focuses on the use of microblogging for information exchange purposes (Ebner, Lienhardt, Rohs, \& Meyer, 2010; Hughes \& Palen, 2009; Jansen et al., 2009) we aim to provide further insights on the factors that increase the influential power of Twitter users by contrasting the following regression equation:

$$
\begin{aligned}
\mathrm{I}_{\mathrm{i}}= & \beta_{0}+\beta_{1} \mathrm{LD}_{\mathrm{i}}+\beta_{2} \mathrm{~F}_{\mathrm{i}}+\beta_{3} \mathrm{MC}_{\mathrm{i}}+\beta_{4} \mathrm{PS}_{\mathrm{i}}+\beta_{5} N S_{\mathrm{i}}+\beta_{6} H_{\mathrm{i}}+\beta_{7} \mathrm{M}_{\mathrm{i}} \\
& +\beta_{8} \mathrm{~L}_{\mathrm{i}}+\mathrm{e}_{\mathrm{i}}
\end{aligned}
$$

\section{Methodology}

As mentioned before, Twitter is the most important microblogging virtual community in the world. Users share public tweets on the platform talking about their interests, opinions or sentiments so there are no ethical or legal issues that impede us to collect information, as the case of Facebook. The PIAR tool developed by the BISITE research group collects chronological information about Twitter users talking about a particular topic by means of a keyword. This tool gives researchers a wide range of data containing a geographical activity maps, sentiment maps or tag-clouds. For the purposes of this study, we will use the part of the tool that, using graph theory, builds virtual communities around selected keywords from the Japanese automotive sector.

When a user follows comments or retweets another user, the 
PIAR tool creates a soft link (unidirectional) between them. However, when users mutually follow, the software builds a strong link (bi-directional) meaning the relation is stronger.

\subsection{Sample selection}

In order to identify the sector used for this study, we have chosen the Japanese automotive sector due to its importance on Japanese economy. Cars are the main exportation product and one of the industrial bases of the Japanese country (Oficina Económica y Comercial de España en Tokio, 2013). Within this strategic sector, Japan is between the top 10 world car producers, being Toyota the leader in this manufacturing industry. After the 2009 crisis and its large impact on vehicle sales, the automotive sector is trying to normalize in terms of reputation and benefits. Furthermore, recent sector scandals make it relevant the analysis of this sector in order to identify the influencers' relevance on the social network sites. By doing so, companies and brands can manage their social networks in order to avoid online reputation crisis that rapidly spread thanks to the influence power of some of their followers.

Researchers collected tweets and data from Spanish-speaking Twitter users using the PIAR platform. We got al tweets from users that were posting using either "Toyota" or "Nissan" as keywords. This does not necessarily mean they need to add the \# sign before the word (indicating a hashtag); we only need them to write one of these words to collect their data. In total, information from 3853 Twitter users was collected from 13th to 25 April 2015, resulting in more than 30,000 tweets. Descriptive statistics and correlations are shown in Tables 1 and 2. Once we obtained those statistics, and in order to improve the results of the analysis, we choose the most adequate measure for each of the variables (see section 3.2). For example, it is more adequate to measure the mentions' variable using a binary variable due to its low dispersion.

We analyzed the data using a multiple-regression model with the stepwise method using IBM SPSS Statistics 23.0 version to perform the analysis. We introduced all variables mentioned above that could have an impact on the social influence of a user. The stepwise regression method does multiple regression models a number of times, eliminating the weakest correlated variable each time. The final model leaves the variables that explain the distribution best. The only statistical requirements are that the data are normally distributed and that there is no collinearity between the independent variables. We have tested the sample for multicollinearity within the independent variables. The suggested cut off for the tolerance value according to Hair, Black, Babin, and Anderson (2010) is 0.10 (or a corresponding VIF of 10.0). Since we do not encounter values at this level, multicollinearity problems are not present in this dataset.

\subsection{Measures}

- Influence (I), the dependent variable of this study, was measured with an index calculated by the PIAR software. This index, ranking from 1 to 100 , has a high coefficient determination with the Klout score. This indicator is based on the users' followers to evaluate their popularity and influence on the social network (Carr \& Brock, 2013).
Table 2

Correlations.

\begin{tabular}{lllll}
\hline Variables & Influence & Lexical_diversity & Followings & Mean_character \\
\hline Influence & 1 & & & \\
Lexical_diversity & -0.004 & 1 & & \\
Followings & $0.591^{* *}$ & 0.006 & 1 & \\
Mean_character & 0.376 & 0.458 & 0.699 & 1 \\
\hline
\end{tabular}

${ }^{* *} \mathrm{p}<0.01$.

- The variable mean_character (MC) collects the number of characters (on average) a user tweets during the data collection period.

- Lexical diversity (LD) captures the ratio between the unique words a user posts on a tweet divided by the total number of words he/she has written in the data collection period. Ranking from 0 to 1 , this metric becomes more relevant as the number of tweets published by a user increases.

- Sentiment polarity (S) reflects the alternative sentiments (positive, negative, neutral) expressed by a Twitter user during the data collection period. In order to test these sentiments, we created two dummy variables one reflecting positive feelings (positive_sentiment) and the other one to show negative ones (negative_sentiment).

- The following (F) variable captures the number of users an individual follows on Twitter.

We also collect the number of hashtags (H), links (L) and mentions (M) that a user has posted on Twitter during the data collection period. Although the majority of users of the sample do not regularly use these elements on their tweets, we include binary variables to test if these elements are present on the most influential Twitter users.

\section{Results}

As we mentioned before, we analyzed the data using a multipleregression model with the stepwise method. Results of the multiple-regression test are shown in Table 3.

The proposed model is statistically significant and it explains $36 \%$ of the variance of the influence score of Twitter users. Hypothesis 1 proposed that users with more following on Twitter would increase their social influence, which received support from the data (beta $=0.008, p<0.000$ ). Social media websites enable the diffusion of eWOM information among the huge amount of people registered on these platforms. Users can even express their thoughts and feelings by forwarding a post from someone they follow, meaning they agree with the tweet (Chu \& Kim, 2011; Sohn, 2014). Regarding the mean characters of a tweet, results do not provide support for $\mathrm{H} 2 \mathrm{a}$ as the effect is non-significant. We also did not find significant results for lexical diversity in this dataset. There is a large amount of information available on a virtual community. People tend to engage with the information if they believe is trustworthy and accurate (Chu \& Kim, 2011) so influencers with lower lexical diversity can be considered as experts on a particular field (with a reduced lexicon, as it is always around the same topic). Since we are specifically two brands within the automotive sector,

Table 1

Descriptive statistics.

\begin{tabular}{|c|c|c|c|c|c|c|c|c|}
\hline Variables & Influence & Lexical diversity & Followings & Mean_character & Sentiment_polarity & Mentions & Hashtags & Links \\
\hline Mean & 38.83 & 0.78 & 458.91 & 109.21 & 0.12 & 0.28 & 0.19 & 0.51 \\
\hline SD & 7.80 & 0.21 & 560.8 & 33.22 & 0.48 & 0.45 & 0.39 & 0.50 \\
\hline
\end{tabular}


Table 3

Regression results.

\begin{tabular}{|c|c|c|c|c|c|}
\hline Dependent variable & Independent variables & Beta & Tolerance & VIF & Model fit \\
\hline \multirow[t]{9}{*}{ Influence (I) } & Constant & $35.009^{* * *}$ & & & $\mathrm{R}$ square $=0.361$ (adjusted $\mathrm{R}$ square $=0.360) ; \mathrm{F}=433.776^{* * *}$ \\
\hline & Lexical_diversity & n.s & 0.837 & 0.782 & \\
\hline & Followings $(\mathrm{F})$ & $0.008^{* * *}$ & 0.982 & 1.018 & \\
\hline & Mean_Character (MC) & n.s & 1.001 & 0.817 & \\
\hline & Positive_sentiment (PS) & $0.728^{* *}$ & 0.956 & 1.046 & \\
\hline & Negative_sentiment (NS) & n.s & 0.951 & 0.817 & \\
\hline & Hashtags $(\mathrm{H})$ & $0.698^{*}$ & 0.817 & 1.224 & \\
\hline & Mentions (M) & $1.379^{* * *}$ & 0.867 & 1.153 & \\
\hline & Links (L) & $-1.017^{* * *}$ & 0.876 & 1.142 & \\
\hline
\end{tabular}

${ }^{*} \mathrm{p}<0.05 ;{ }^{* *} \mathrm{p}<0.01 ;{ }^{* * *} \mathrm{p}<0.001 ;$ n.s: non significant.

it is reasonable to think that the vocabulary around this topic is reduced.

We found partial support for $\mathrm{H} 2 \mathrm{~b}$, because tweets showing positive sentiment contribute to increase users' social influence (beta $=0.728, \mathrm{p}<0.01$ ). This result is consistent with Bae and Lee (2012) research when the audience tends to respond to "positive tweets of a popular user" with positive retweeting. However, we found no empirical evidence on the effects of negative sentiments written on tweets on users' influence (H2b). Again, many users will engage in social media as "opinion seekers" (Chu \& Kim, 2011). If influencers are loyal to their community, they will be willing to express their feelings and emotions about a particular product or brand, providing a valuable, satisfactory answer to many of their followers. Lastly, and regarding the characteristics of tweets, we found support for $\mathrm{H} 3 \mathrm{a}$ and $\mathrm{H} 3 \mathrm{~b}$. Using hashtags or mentions contributes to increase users' social influence (beta $=0.650, \mathrm{p}<0.05$ and beta $=1.379, \mathrm{p}<0.000$ ). On the contrary, we could not support $\mathrm{H} 3 \mathrm{c}$ about the use of links, as the effect is contrary to hypothesized (beta $=-1.017, p<0.000$ ). In conclusion, except for lexical diversity, mean_character and links which results were contrary to expected, we found significant support for all the proposed hypotheses. The results provide insightful knowledge for companies, brands and organization. For example, whenever an online reputation crisis explodes, companies can easily locate influencers on the virtual platform to see if they are supporting or criticizing the brand.

\section{Discussion}

e-WOM transmitted through social media has become a determinant factor for businesses and brands. Therefore, one question that is of concern in the present study is to help identify influencers that spread the right message from a company's perspective. Next, we need to identify which factors do influential individuals share so we can recruit and convince those relevant for a marketing campaign (Kumar \& Mirchandani, 2012).

On examining Twitter users, it was found that influencers present characteristics that clearly distinguish them from the rest of the users of their virtual community. First, influencers are individuals that follow many Twitter users. Although the PIAR platform also collects data from the number of followers, we could not use this indicator in our analysis, as it forms part of the influence metric. However, the fact that an influencer significantly follows more users is a sign of tweet projection. Since those users get a higher tweet reach when they post, there is a greater change of engagement (meaning a favorite, a retweet, a reply ...) when influencers write, compared to those with less power in the social network. The diffusion of tweets expands when a Twitter user is an influencer, contributing to spread e-WOM on the topic he/she is talking about (Toyota and Nissan brands on this case). Some authors also indicate that trust in social network's friends is a key factor to generate global trust in social networks (Cordero-
Gutiérrez \& Santos-Requejo, 2016).

Regarding the use of hashtags, Twitter is a tool that facilitates users' keyword search via the \# sign. This means that users can follow current trends by looking for hashtags online. Consequently, influencers use tags on their posts knowing to catch users' attention, therefore increasing engagement (Cooper, 2013). Hashtags create, on a different color that the rest of the tweet, a set of relevant words around a topic. If a user is interested on a particular Twitter conversation, it is very easy to find the information by clicking on the hashtag. This is the reason why using hashtags make influencers' tweets more relevant. This is also the case when influencers use mentions on their links. Mentions directly engage users into the conversation, and they contribute to strengthen the links between the members of the virtual community.

We found no significant evidence to prove that the number of characters of a tweet is also significant for influencers' power. We believe that the large amount of data regarding Toyota posted on that period could make it less relevant, affecting influencers' authority. Nevertheless, the ideal number of characters of a tweet is a controversial issue as some authors think that the longer the tweet the more relevant and interesting is for users (Tao, Abel, Hauff, \& Houben, 2012), whereas other research indicate that tweets with less than 100 characters get $17 \%$ more engagement (Sales Force, 2012).

The lexical diversity variable presents no significant effect on a users' social influence on this dataset. We believe that influencers are experts on a particular field, so they tend to use a set of similar words on all his/her tweets around a topic. In this case, if influencers are talking about Nissan and Toyota, they are probably repeating a set of words regarding the characteristics of the vehicles, the price and news related with these brands. This means their lexical diversity is smaller, but just because the lexicon around a particular topic such as automobiles is limited. Furthermore, influencers use an adapted language that all their followers understand. On the contrary, users using a high lexical diversity indicate that they talk about a wide range of topics, meaning they are not specialists on any of them. They join the conversation mostly to express their personal opinion about current trending topics. Messias et al. (2013) also affirm that users increase their influence score when tweeting about a specific subject. Therefore, becoming a specialist has a positive influence on social engagement.

Some authors consider that, in line with this study, using links does not help tweets to get more engagement: retweets, favorites, and mentions (Lee, 2015) and that tweets containing links get less interactions that others containing photos or text only (Ross, 2014). In our sample, influencers use, on average less embedded links that regular Tweet users. The reason could be that Twitter users look for the immediacy and the great amount of information they can collect from the platform in a short time. When users click on a link, they are transferred to a new browser tab with unknown content. 
Many users mistrust tweets with links, as they perceive it as spammers with malicious content (Benevenuto et al., 2010). On the contrary, if influencers provide them with perceived trustworthy information, they do not need to consult alternative sources of data so often. Customers tend to rely more on customers' opinions than on firms' referrals, as they are perceived as "honest and accurate" (Lahuerta-Otero, Muñoz-Gallego \& Pratt, 2014). If users feel comfortable with a conversation around a hashtag, there is no need to enrich the conversation by using external elements. Influencers and the content of the conversation is powerful enough to get users involved and to pass the message along, generating e-WOM.

Lastly, we also found support to affirm that users showing positive sentiments get higher social influence on Twitter. We need to remind that we measure sentiment by means of two dummy variables, meaning that an influencer can have equal influence by writing positive or negative comments on the social platform. Results also confirm that influencers tend to engage more with users by writing positive tweets. This means that influencers really implicate in conversations by expressing emotions and personal feelings that go beyond a mere neutral message. Note an example on the following tweet (see Fig. 1):

The tweet says: "What do you think? \#WithMaryRabago \#HighlanderHybrid \#Let'sGoTogether thanks @Toyota friends" and it was published on April 15, 2015. The user that wrote it has a 50.94 influence score (percentile 66 is 42.53). Thus, we can consider her as an influencer. The sentiment score for this user indicates that she is not a neutral one, as she writes words such as "thanks" or "friends" on her tweets, which prove strong positive sentiments toward the brand. This particular example also includes a picture of the Toyota vehicle as well as three hashtags and a Toyota mention.
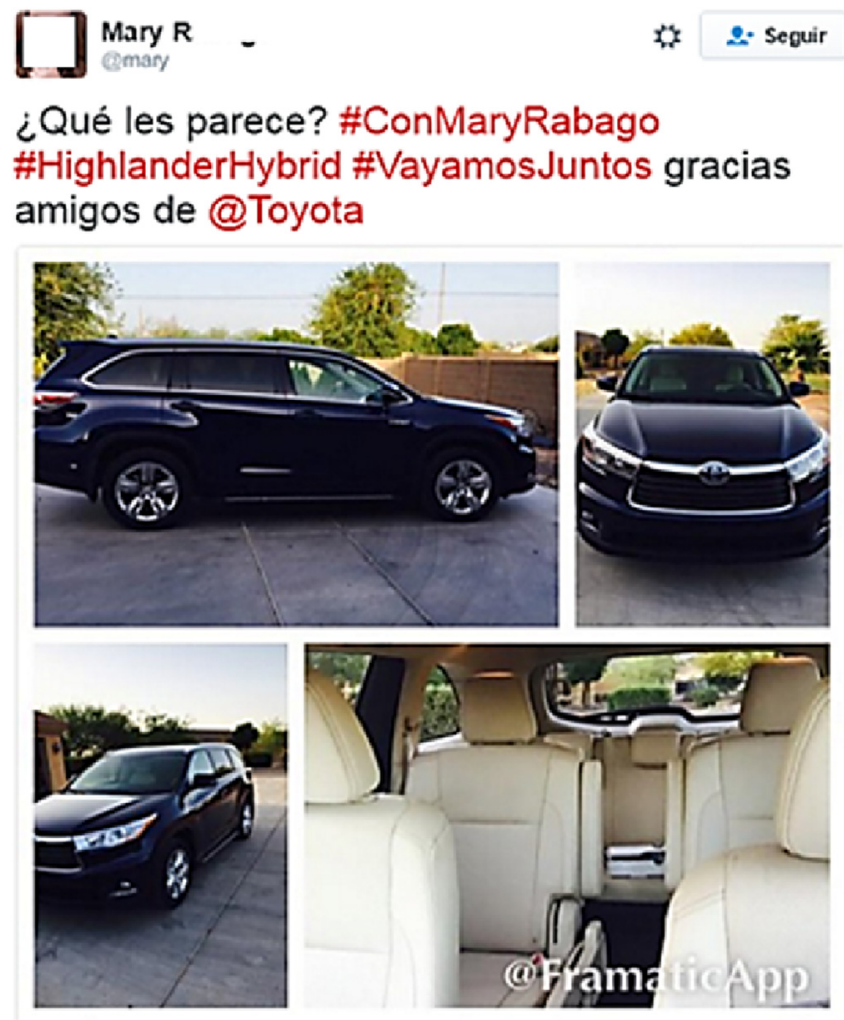

$0.58-15$ abc, 2015

Fig. 1. Tweet example.

\section{Conclusion}

The ability to influence users is a valuable tool that companies can use to favor their marketing campaigns. Since customers change and become socially connected, the way firms address they needs has to change, too. Despite the vast amount of individual and relationship data available through these platforms, most organizations have been unable to measure the effectiveness of their social media strategy (Kumar \& Mirchandani, 2012). By analyzing the characteristics of influencers and their tweets, we are able to track them better, monitor their conversations and decide if they can become a valuable resource to our brand.

As Okazaki et al. (2014) posit, prosumers tend to create a more complex social network, so firms are strongly encourage to use data mining techniques in order to identify them. Since influencers can act as prosumers, they usually engage in collaboration and participation with firms. Properly motivated, they can participate in the co-creation of the advertising message helping companies to leverage on e-WOM (Jin \& Phua, 2014). These opinion leaders can also help companies and brands to improve product design features or their customer service as they are energetic and they write about their feelings when using a product. Hence, they are willing to provide an extremely valuable feedback which firms can take advantage of in order to gain market competitiveness.

This research proposes a method to determine which users are able to exert a great influence on their followers. As companies cannot know the Klout score of each of their followers, it is important to observe alternative users' characteristics (such as the number of links, tweet words, mentions or hashtags) to determine if that user will eventually exert a determinant influential power on other members of the virtual community. Social media provides an excellent channel for building a consumer-brand relationship so marketers need to identify influencers to boost them to spread positive eWOM to their audiences, as they are a cost-effective way to pass along a trustworthy message (Chu \& Kim, 2011).

Second, SNSs provide an essential channel for building a consumer-brand relationship. Marketers should try to identify 'social influencers' in SNSs, encourage users of SNSs to spread positive eWOM regarding selected brands and discourage them from sharing negative information with their personal networks. Third, the interactivity of SNSs as a medium allows advertisers to reach a voluntary, segmented audience in a cost-effective way compared to other media.

Further research intends to perform a complementary analysis based on more than 30,000 tweets generated by the Twitter users on the present study on the data collection period. By means of content analysis using netnography techniques (Kozinets, 2009) we intend to gain further insights about influencers and the type of content they publish online.

Although this study presents some of the first research that empirically examines influencers' characteristics, a few limitations should be noted. First, sample only contains data from Spanishspeaking users talking about two particular brands: Toyota and Nissan. Nevertheless, Spanish is the second most used language on Twitter and Facebook across the world, with an enormous potential growth. For example, it is the main language used on Twitter on Anglo-Saxon cities such as London or New York (Instituto Cervantes, 2015). PIAR software is under development to incorporate more languages to the analysis, so future research should replicate this study with tweets in different languages to compare results. Furthermore, the data collection period only last 12 days. Users sent millions of tweets everyday so further research should enlarge the sample and conduct longitudinal studies to see if results are robust over time. We could also look for a specific emergency event (or an online reputation crisis) to see if influencers 
tweet differently under pressure or analyze events in different sectors to evaluate if results change. Lastly, this tool only collects data for Twitter. Although is the most suitable tool to look for influencers (Augure, 2015) future research should try alternative methods to look for influencers in other relevant social media sites such as Facebook, LinkedIn or blogs.

\section{Acknowledgements}

This work was supported by the Ministry of Industry, Energy and Tourism (Strategic actions of economy and society 2013. PIAR: Plataforma Inteligente para la Detección de Amenazas en la Red [grant number TSI-100201-2013-20].

\section{References}

Augure. (2014). Informe Augure sobre el estatus del marketing the influencers. available at: http://www.augure.com/es/blog/influencer-marketing-estatus20140220 (accessed 01.08.16.).

Augure. (2015). Estatus y prácticas de las relaciones con influencers en 2015. available at: http://www.augure.com/es/blog/estudio-relaciones-influencers-20150616 (accessed 05.08.16.).

Babić, A., Sotgiu, F., de Valck, K., \& Bijmolt, T. (2015). The effect of electronic word of mouth on sales: A meta-analytic review of platform, product, and metric factors. Journal of Marketing Research. http://dx.doi.org/10.1509/jmr.14.0380. InPress.

Bae, Y., \& Lee, H. (2012). Sentiment analysis of Twitter audiences: Measuring the positive or negative influence of popular twitterers. Journal of the American Society for Information Science and Technology, 63(No. 12), 2521-2535.

Benevenuto, F., Magno, G., Rodrigues, T., \& Almeida, V. (2010). Detecting spammers on twitter. In Collaboration, electronic messaging, anti-abuse and spam conference (CEAS), 6(12)

Bennet, S. (2014). The optimal length of a tweet, hashtag, podcast, slideshare and (almost) everything online. available at: http://www.adweek.com/socialtimes/ ideal-length-social-media-podcast-blog/502513.

Bergami, M., \& Bagozzi, R. P. (2000). Self-categorization, affective commitment, and group self-esteem as distinct aspects of social identity in an organization. British Journal of Social Psychology, 39(No. 4), 555-577.

Bhattacharya, C. B., \& Sen, S. (2003). Consumer-company identification: A framework for understanding consumers' relationships with companies. Journal of Marketing, 67(No. 2), 76-88.

Bifet, A., \& Frank, E. (2010). Sentiment knowledge discovery in twitter streaming data. In Discovery science (pp. 1-15). Springer Berlin Heidelberg.

Bigonha, C., Cardoso, T. N., Moro, M. M., Almeida, V. A., \& Gonçalves, M. A. (2010). Detecting evangelists and detractors on twitter. In 18th Brazilian symposium on multimedia and the web (pp. 107-114).

Blanchard, A. L. (2008). Testing a model of sense of virtual community. Computers in Human Behavior, 24(No. 5), 2107-2123.

Bongwon, S., Lichan, H., Peter, P., \& Chi, E. H. (2010). Want to be retweeted? Large scale analytics on factors impacting retweet in twitter network. In IEEE international conference on privacy, security, risk and trust (pp. 177-184).

Boyd, D., Golder, S., \& Lotan, G. (2010). Tweet, tweet, retweet: Conversational aspects of retweeting on twitter. In System sciences (HICSS), 2010 43rd Hawaii international conference on (pp. 1-10). IEEE.

BusinessDictionary. (2015). Definition of influencer. Available at: http://www. businessdictionary.com/definition/influencers.html (accessed 12.09.15.).

Carr, G., \& Brock, T. (2013). Klout matters: How to engage customers, boost your digital influence-and raise your Klout score for success. McGraw Hill Professional.

Cha, M., Haddadi, H., Benevenuto, F., \& Gummadi, K. P. (2010). Measuring user influence in Twitter: The million follower fallacy. In Proceedings of the international AAAI conference on weblogs and social media. Menlo Park, CA: Association for the Advancement of Artificial Intelligence.

Chu, S. C., \& Kim, Y. (2011). Determinants of consumer engagement in electronic word-of-mouth (eWOM) in social networking sites. International Journal of Advertising, 30(No. 1), 47-75.

Cooper, B. (2013). 10 surprising new twitter stats to help you reach more followers. available at: https://blog.bufferapp.com/10-new-twitter-stats-twitter-statisticsto-help-you-reach-your-followers (accessed 12.28.16.).

Cordero-Gutiérrez, R., \& Santos-Requejo, L. (2016). Intention to participate in online commercial experiments by social network's users: Differences in gender and age. Management Reserach Review, 39, No. 4, 378-398.

Corvey, W. J., Vieweg, S., Rood, T., \& Palmer, M. (2010, June). Twitter in mass emergency: What NLP techniques can contribute?. In Proceedings of the NAACL HLT 2010 workshop on computational linguistics in a world of social media ( $\mathrm{pp}$. 23-24). Association for Computational Linguistics.

Dann, S. (2010). Twitter content classification. First Monday, 15(2). available at: http://firstmonday.org/ojs/index.php/fm/article/view/2745/2681 (accessed 12.09.15.).

Davenport, T. H., \& Beck, J. C. (2002). The attention economy: Understanding the new currency of business. Cambridge, MA: Harvard Business Press.
Davis, A., \& Khazanchi, D. (2008). An empirical study of online word of mouth as a predictor for multi-product category e-Commerce sales. Electronic Markets, 18(No. 2), 130-141.

Dharmavaram Srenivasan, N., Sian Lee, C., \& Hoe-Lian Goh, D. (2012). Tweeting the friendly skies: Investigating information exchange among Twitter users about airlines. Program, 46(No. 1), 21-42.

Dholakia, U. M., Bagozzi, R. P., \& Pearo, L. K. (2004). A social influence model of consumer participation in network-and small-group-based virtual communities. International Journal of Research in Marketing, 21(No. 3), 241-263.

Duana, W., Gub, B., \& Whinston, A. B. (2008). Do online reviews matter?- An empirical investigation of panel data. Decision Support Systems, 45(No. 3), 1007-1016.

Ebner, M., Lienhardt, C., Rohs, M., \& Meyer, I. (2010). Microblogs in higher education -A chance to facilitate informal and process-oriented learning. Computers and Education, 92-100. No. 55.

eMarketer. (2014). Poor service leads brits to scream, shout and post on social. available at: http://www.emarketer.com/Article/Poor-Service-Leads-BritsScream-Shout-Post-on-Social/1011100\#sthash.Yun1A5uT.dpuf (accessed 12.18.15.).

Enge, E. (2014). Twitter engagement unmasked: A study of more than 4M Tweets. available at: https://www.stonetemple.com/twitter-engagement-umasked/.

Erkan, I., \& Evans, C. (2016). The influence of eWOM in social media on consumers purchase intentions: An extended approach to information adoption. Computers in Human Behavior, 61, 47-55.

Flavián, C., \& Guinalíu, M. (2005). The influence of virtual communities on distribution strategies in the internet. International Journal of Retail \& Distribution Management, 33(No. 6), 405-425.

Ghosh, S., Viswanath, B., Kooti, F., Sharma, N. K., Korlam, G., Benevenuto, F., et al (2012). Understanding and combating link farming in the twitter social network. In Proceedings of the 21st international conference on world wide web (pp. 61-70). ACM.

Goh, D. H., \& Lee, C. S. (2011). ‘Gone too soon': Did Twitter grieve for Michael Jackson? Online Information Review, 36(1).

Goulder, A. W. (1960). The norm of reciprocity: A preliminary statement. American Sociological Review, 161-178. No. 25.

Hair, J. F., Black, W. C., Babin, B. J., \& Anderson, R. E. (2010). Multivariate data analysis (7th ed.). Pearson.

Henning-Thurau, T., Gwinner, K. P., Walsh, G., \& Gremler, D. D. (2004). Electronic word-of-mouth via consumer-opinion platforms: What motivates consumers to articulate themselves on the internet? Journal of Interactive Marketing, 38-52. No.18.

Hughes, A. L., \& Palen, L. (2009). Twitter adoption and use in mass convergence and emergency events. International Journal of Emergency Management, 6(No. 3/4) $248-260$.

Hutchison, K., \& Kumara, S. (2013). Big data analytics-sentiment analysis of Twitter data using clustering techniques. In IIE annual conference. Proceedings (p. 2495). Institute of Industrial Engineers-Publisher.

Ikeda, K., Hattoril, G., Ono, C., Asoh, H., \& Higashino, T. (2013). Twitter user profiling based on text and community mining for market analysis. Knowledge-Based Systems, 35-47. No. 51.

Instituto Cervantes. (2015). El español en el mundo. available at: http://www. cervantes.es/sobre_instituto_cervantes/prensa/2016/noticias/anuario-delespanol-2015.htm.

Internet Live Stats. (2015). Internet usage and social media statistics. available at: http://www.internetlivestats.com/ (accessed 01.03.16).

Jansen, B. J., Zhang, M., Sobel, K., \& Chowdury, A. (2009). Twitter power: Tweets as electronic word of mouth. Journal of the American Society for Information Science and Technology, 60(No. 9), 1-20.

Java, A., Song, X., Finin, T., \& Tseng, B. (2007). Why we Twitter: Understanding microblogging usage and communities. In H. Zhang, B. Mobasher, C. L. Giles A. McCallum, O. Nasraoui, M. Spiliopoulou, et al. (Eds.), Proceedings of the ninth WebKDD and first SNA-KDD 2007 workshop on web mining and social network analysis (pp. 56-65). New York, NY: ACM.

Jin, S. A. A., \& Phua, J. (2014). Following celebrities' tweets about brands: The impact of twitter-based electronic word-of-mouth on consumers' source credibility perception, buying intention, and social identification with celebrities. Journal of Advertising, 43(No. 2), 181-195.

Klout. (2016). The klout score. available at: https://klout.com/corp/score.

Kozinets, R. V. (2009). Netnography: Doing ethnographic research online. London: Sage Publications Limited.

Kumar, V., \& Mirchandani, R. (2012). Increasing the ROI of social media marketing MIT Sloan Management Review, 54(No. 1), 55.

Lahuerta-Otero, E., Muñoz-Gallego, P. A., \& Pratt, R. (2014). Click-and-Mortar SMEs: Attracting customers to your website. Business Horizons, 57, No. 6, 729-736.

Lee, K. (2015). What analyzing 1 million tweets taught us. available at: http://tnw.to/ s3R2i (accessed 07.29.15.).

Liu, Z., Liu, L., \& Li, H. (2012). Determinants of information retweeting in microblogging. Internet Research, 22(No. 4), 443-466.

Malhotra, A., Malhotra, C. K., \& See, A. (2012). How to get your messages retweeted. MIT Sloan Management Review, 53(No. 2), 61-66.

Messias, J., Schmidt, L., Oliveira, R., \& Benevenuto, F. (2013). You followed my bot! Transforming robots into influential users in Twitter. First Monday, 18(No. 7).

Meyer, J. P., Stanley, D. J., Herscovitch, L., \& Topolnytsky, L. (2002). Affective, continuance, and normative commitment to the organization: A meta-analysis of antecedents, correlates, and consequences. Journal of Vocational Behavior 
20-52. No. 61.

Naaman, M., Boase, J., \& Lai, C. H. (2010). Is it really about me?: Message content in social awareness streams. In Proceedings of the 2010 ACM conference on Computer supported cooperative work (pp. 189-192). ACM.

Oficina Económica y Comercial de España en Tokio. (2013). Informe económico y comercial. Available at: http://www.iberglobal.com/files/japon_iec.pdf (accessed 11.29.15.).

Okazaki, S., Díaz-Martín, A. M., Rozan-Suplet, M., \& Menéndez-Benito, H. D. (2014). Explotando datos de Twitter: cómo captar las relaciones entre clientes. In Experiencia y comportamiento del cliente en un entorno multicanal: Claves de éxito para fabricantes y detallistas (pp. 379-397). Oviedo (Spain): Cátedra Fundación Areces de Distribución Comercial. ISBN: 978-84-8367-469-7.

Pal, A., \& Counts, S. (2011). Identifying topical authorities in microblogs. In Proceedings of the fourth ACM international conference on web search and data mining (pp. 45-54).

Park, C. \& Lee, T. M. (2009). Information direction, website reputation and eWOM effect: A moderating role of product type. Journal of Business Research, 62(No. 1), $61-67$.

Parra-López, E., Bulchand-Gidumal, J., Gutiérrez-Tano, D., \& Díaz-Armas, R. (2011). Intentions to use social media in organizing and taking vacation trips. Computers in Human Behavior, 27(No. 1), 640-654.

Postmes, T., Spears, R., \& Lea, M. (2000). The formation of group norms in computermediated communication. Human Communication Research, 26(No. 3), 341-371.

Reynolds, G. (2006). An army of Davids: How markets and technology empower ordinary people to beat big media, big government, and other Goliaths. Nashville TN: Thomas Nelson.

Rheingold, H. (1993). The virtual community: Homesteading on the electronic frontier New York, NY: Harper Perennial.

Ross, P. (2014). Photos get the most engagement on Twitter. available at: http://www. socialbakers.com/blog/2306-photos-get-the-most-engagement-on-twitter (accessed 12.09.15.).

Russell, M. A. (2013). Mining the social web: Data mining Facebook, Twitter, LinkedIn, Google+, GitHub, and more. O'Reilly Media, Inc.

Sales Force. (2012). Strategies for effective Tweeting: A statistical review. available at: http://www.salesforcemarketingcloud.com/wp-content/uploads/2013/03/ Strategies-for-effective-tweeting.pdf.

San José-Cabezudo, R., \& Camarero-Izquierdo, C. (2012). Determinants of openingforwarding e-mail messages. Journal of Advertising, 41(No. 2), 97-112.
Sankaranarayanan, J., Samet, H., Teitler, B. E., Lieberman, M. D., \& Sperling, J. (2009). TwitterStand: News in tweets. In GIS '09: Proceedings of the 17th ACM SIGSPATIAL international conference on advances in geographic information systems ( $\mathrm{pp}$. 42-51). New York, NY: ACM.

Schuler, D. (1996). New community networks - Wired for change. Reading, MA: Addison-Wesley.

Social Media Today. (2015). 10 amazing social media growth stats from 2015. available at: http://www.socialmediatoday.com/social-networks/kadie-regan/2015-0810/10-amazing-social-media-growth-stats-2015 (accessed 01.04.16.).

Sohn, D. (2014). Coping with information in social media: The effects of network structure and knowledge on perception of information value. Computers in Human Behavior, 32, 145-151. http://doi.org/10.1016/j.chb.2013.12.006.

Starbird, K., Palen, L., Hughes, A. L., \& Vieweg, S. (2010). Chatter on the red: What hazards threat reveals about the social life of microblogged information. In Proceedings of the 2010 ACM conference on computer supported cooperative work (pp. 241-250). New York, NY: ACM.

Tao, K., Abel, F., Hauff, C., \& Houben, G. J. (2012). What makes a tweet relevant for a topic. Making Sense of Microposts, 49-56 (\# MSM2012).

Twitter. (2015). About the company. available at: https://about.twitter.com/es/ company.

Twitter. (2016). The Twitter glossary. available at: https://support.twitter.com/ articles/166337.

Urban, G. (2005). Don't just relate advocate: A blue print for profit in the era of customer power. Upper Saddle River, NJ: Wharton School Publishing.

Verhoef, P. C., Beckers, S. F., \& Van Doorn, J. (2013). Understand the perils of cocreation. Harvard Business Review, 91(No. 9).

Vieweg. S., Hughes, A. L., Starbird, K. \& Palen, L. (2010, April). Microblogging during two natural hazards events: What Twitter may contribute to situational awareness?. In Proceedings of the SIGCHI conference on human factors in computing systems (pp. 1079-1088). ACM.

Weng, J., Lim, E. P., Jiang, J., \& He, Q. (2010, February). Twitterrank: Finding topicsensitive influential twitterers. In Proceedings of the third ACM international conference on Web search and data mining (pp. 261-270). ACM.

Zarrella, D. (2009). Science of retweets. available at: http://danzarrella.com/scienceof-retweets.pdf (accessed 03.15.16.).

Zhang, L., Peng, T. Q., Zhang, Y. P., Wang, X. H., \& Zhu, J. J. (2014). Content or context: Which matters more in information processing on microblogging sites. Computers in Human Behavior, 31, 242-249. 